\title{
Expressão gênica das células do cumulus oophorus de bovinos após a vitrificação*
}

\author{
Gene expression of bovine cumulus oophorus cells after vitrification \\ Felipe Lohmann Arend', Arnaldo Diniz Vieira², Matheus Pedrotti de Cesaro², Alceu Mezzalira², \\ Alexandre Tavares Duarte de Oliveira ${ }^{3} \&$ Rui Fernando Felix Lopes ${ }^{1}$
}

\begin{abstract}
RESUMO
Um dos desafios da criobiologia continua sendo o desenvolvimento de um método que proporcione a manutenção da viabilidade após a criopreservação de oócitos imaturos na espécie bovina. A vitrificação tem sido a metodologia que proporciona resultados de sobrevivência após a criopreservação mais promissores para complexos cumulus-oócito (CCOs) imaturos bovinos. Entretanto, a ação dos crioprotetores sobre as células do cumulus oophorus, no que diz respeito à regulação da expressão de genes importantes nesta fase, ainda é pouco compreendida. O objetivo do trabalho foi avaliar a expressão gênica das proteínas ácido hialurônico sintase 2 (HAS2), link protein (HAPLN1), conexina 43 (GJA1) e proteína de choque térmico HSP70-1 (HSP70-1) em células do cumulus oophorus de oócitos imaturos bovinos submetidos a exposição e/ou vitrificação na solução crioprotetora (SV) composta por $20 \%$ de etileno glicol (EG) $+20 \%$ dimetil sulfóxido (DMSO) + 0,5M de sacarose. Os CCOs foram selecionados e distribuídos em 4 grupos experimentais: Gl, CCOs não submetidos a maturação in vitro (MIV); G2, CCOs submetidos à MIV; G3, CCOs maturados após a exposição à SV; e G4, CCOs maturados após a vitrificação com a SV. A MIV foi realizada em TCM 199, suplementado com soro de égua em estro, à $39^{\circ} \mathrm{C}, 5 \%$ de $\mathrm{CO}_{2} \mathrm{e}$ máxima umidade relativa, por 22 a 24 horas. A extração do RNA das amostras de células do cumulus foi realizada pelo método do fenol-clorofórmio seguido por uma etapa de captação específica do mRNA. Após a utilização da técnica de RT-PCR para a obtenção do cDNA e amplificação dos quatro fragmentos específicos, a análise dos resultados não mostrou diferença significativa entre os grupos para a abundância relativa dos transcritos de link protein $(\mathrm{p}=0,486)$, HAS2 $(\mathrm{p}=0,394)$, conexina 43 $(\mathrm{p}=0,116)$ e $H S P 70-1 \quad(\mathrm{p}=0,248)$.
\end{abstract}

Descritores: cumulus oophorus, expressão gênica, maturação in vitro, vitrificação.

\begin{abstract}
A challenge of cryobiology remains in to develop a method that provides adequate results of viability after cryopreservation of immature bovine oocytes. Vitrification has been the methodology that provides most promising survival results after cryopreservation for immature bovine cumulus-oocyte complexes (COCs). However, the action of cryoprotectants on the gene expression regulation of cumulus oophorus cells is still poorly understood. The aim of this study was to evaluate, through the RT-PCR technique, the gene expression of hyaluronic acid synthase protein 2 (HAS2), link protein, connexin 43 and heat shock protein 70 (HSP70-1) in cumulus oophorus cells of immature bovine oocytes exposed and/or vitrified in cryoprotectant solution (VS) containing $20 \%$ ethylene glycol (EG) $+20 \%$ dimethilsulfoxide (DMSO) $+0.5 \mathrm{M}$ sucrose before in vitro maturation (IVM). The immature COCs were sellected, and allocated into four experimental groups: G1, COCs no submitted to IVM; G2, COCs submitted to IVM; $G 3$, COCs exposed to VS and submitted to IVM; and $G 4$, COCs vitrified with VS and submitted to IVM. The IVM was performed in TCM 199 supplemented with oestrus mare serum, at $39^{\circ} \mathrm{C}$, under $5 \%$ of $\mathrm{CO}_{2}$ and maximum relative humidity, for 22 to 24 hours. The RNA extraction from cumulus cells samples was performed by using the phenol-chloroform followed by the specific capture of the mRNA. The mRNAs were transcribed into cDNA using RT-PCR to evaluate patterns of gene expression. The results showed no significant difference between the groups tested for the relative abundance of link protein $(\mathrm{p}=0.486)$, HAS2 $(\mathrm{p}=0.394)$, connexin $43(\mathrm{p}=0.116)$ and HSP70-1 $(\mathrm{p}=0.248)$ transcripts.
\end{abstract}

Keywords: cumulus oophorus, gene expression, in vitro maturation, vitrification.

*Trabalho originado da Dissertação do primeiro autor. Programa de Pós-graduação em Ciências Veterinárias (PPGCV), Universidade Federal do Rio Grande do Sul (UFRGS), Porto Alegre, RS, Brasil. ${ }^{1}$ Laboratório de Biotecnologia Animal Aplicada, Instituto de Ciências Básicas da Saúde (ICBS), Departamento de Ciências Morfológicas, UFRGS, Av. Sarmento Leite no. 500, CEP 90050-170 Porto Alegre, RS, Brasil. ${ }^{2}$ Centro de Ciências Agroveterinárias (CAV), Universidade do Estado de Santa Catarina (UDESC), Lages, SC, Brasil. ${ }^{3}$ Universidade Federal de Ciências da Saúde de Porto Alegre (UFCSPA), Porto Alegre, RS, Brasil. CORRESPONDÊNCIA: R. F. F. Lopes [rui.lopes@ufrgs.br Fone + 55 (51) 9991 2332]. 


\section{INTRODUÇÃO}

A obtenção de índices satisfatórios de sobrevivência oocitária após a criopreservaçãoo permite maior flexibilidade na execução de rotinas de maturação, fecundação, cultivo in vitro e transferência nuclear [11]. Exemplos bem sucedidos de vitrificação de oócitos têm sido relatados na espécie bovina [20, $25,30,41,45]$. Entretanto, as taxas de fecundação e desenvolvimento embrionário subsequentes ainda são inferiores às obtidas com oócitos não vitrificados [22]. As razões para esta diferença podem estar relacionadas com velocidades de resfriamento e reaquecimento insuficientes [38] e também com alterações provocadas na comunicação entre o oócito e as células do cumulus oophorus ou na própria viabilidade destas células [33].

As células da granulosa são importantes para o processo de maturação oocitária e, in vivo, o desenvolvimento folicular, maturação e ovulação só ocorrem de forma bem sucedida se há uma comunicação entre as células da granulosa e o oócito [35,42]. Buscar um padrão de expressão dos genes no oócito e nas células da granulosa associado ao processo de maturação in vitro (MIV) é de grande valia para elucidar aspectos que possam aumentar a eficiência do sistema de produção in vitro $[28,48]$.

O objetivo do trabalho foi avaliar a expressão de proteínas de interesse no processo de maturação como, a ácido hialurônico sintase 2 (HAS2; hyaluronan synthase), a link protein (HAPLN1; hyaluronan and proteoglycan link protein 1), a conexina 43 (GJA1; gap junction protein, alpha 1, $43 k D a$ ) e a proteína de choque térmico 70-1 (HSP701; heat shock $70 \mathrm{kD}$ protein 1), em células do cumulus oophorus de oócitos imaturos bovinos submetidos a exposição e/ou vitrificação na solução crioprotetora (SV) composta por $20 \%$ de etileno glicol $(\mathrm{EG})+20 \%$ de dimetil sulfóxido (DMSO) $+0,5 \mathrm{M}$ de sacarose.

\section{MATERIAIS E MÉTODOS}

\section{Complexos cumulus oophporus-oócitos (CCOs)}

Ovários bovinos foram coletados em abatedouro e transportados à temperatura de 24 a $30^{\circ} \mathrm{C}$ em solução salina tamponada com fosfato, adicionado de penicilina $\mathrm{G}$ potássica $(\mathrm{P}-4686)^{1}$ e sulfato de estreptomicina $(\mathrm{S}-1277)^{1}$. Entre cinco a oito horas após o início do abate, os folículos que apresenta- vam diâmetro entre 2 e $8 \mathrm{~mm}$, foram puncionados com uma agulha de $19 \mathrm{G}$ conectada a um tubo de ensaio, ligado a uma bomba de vácuo com pressão suficiente para aspirar 20ml de líquido/min, de acordo com a técnica descrita por Lehmkuhl et al. [17]. Após a punção, os complexos cumulus oophorusoócito (CCOs) foram selecionados e lavados em meio de manipulação (meio TCM199 com sais de Earle; $\mathrm{M}-2520^{1}$ ) adicionado de 5,96mg/ml de Hepes [H $6147]^{1} ; 2,2 \mathrm{mg} / \mathrm{ml}$ de $\mathrm{NaHCO}_{3}(\mathrm{~S}-5761)^{1} ; 2,2 \mu \mathrm{g} / \mathrm{ml}$ de piruvato de sódio $(\mathrm{P}-2256)^{1} ; 50 \mathrm{mg} / \mathrm{ml} \mathrm{de}$ gentamicina $(\mathrm{G}-1264)^{1}$ e $10 \%$ de soro de égua em estro [SEE]). Os CCOs selecionados foram classificados de acordo com as características morfológicas [18] e apenas aqueles que apresentavam camadas compactas de células do cumulus e cujos oócitos mostrassem citoplasma homogêneo foram utilizados.

\section{Grupos experimentais}

Após a seleção, grupos de 5 ou de 25 CCOs foram homogeneamente distribuídos em 4 grupos experimentais: grupo 1 (CNM) - 5 CCOs não submetidos a maturação in vitro (MIV); grupo 2 (MIV) - 25 CCOs submetidos à MIV; grupo 3 (ESV) - 25 CCOs maturados após a exposição à solução de vitrificação (SV); e grupo 4 (VSV) - 25 CCOs vitrificados com a $\mathrm{SV}$, reaquecidos após 24 horas e submetidos à MIV.

Os 5 CCOs do grupo 1 (não submetidos a MIV) foram submetidos ao desnudamento mecânico em agitador de tubos e, em seguida, os oócitos foram recuperados e as células do cumulus concentradas por centrifugação antes do acondicionamento em tubos cônicos de microcentrifuga de $0,5 \mathrm{ml}$ para armazenamento em nitrogênio líquido, visando a preservação do mRNA. Os 25 CCOs de cada um dos demais grupos foram submetidos aos tratamentos específicos de MIV (grupo 2) ou MIV com prévia exposição (grupo 3) ou vitrificação (grupo 4); nestes grupos, após a MIV foram coletados 5 CCOs para serem desnudados e armazenados em nitrogênio líquido de forma idêntica aos CCOs imaturos do grupo 1 .

\section{Vitrificação dos CCOs imaturos e maturação in vitro (MIV)}

A vitrificação foi realizada através da exposição ao nitrogênio líquido em tubos de vidro manualmente estirados. Os CCOs foram inicialmente expostos a solução de equilíbrio (SE) composta por $10 \%$ 
de etileno glicol (EG; E-9129) ${ }^{1}+10 \%$ de dimetil sulfóxido (DMSO; D-2650) ${ }^{1}$ em meio de manipulação. Após 30 segundos de exposição, os CCOs foram expostos a solução de vitrificação (SV) composta de $20 \%$ de $\mathrm{EG}+20 \%$ de DMSO + 0,5M de sacarose $(\mathrm{S}-1888)^{1}$ em meio de manipulação, por 25 segundos. Após este período de exposição os CCOs foram depositados na solução de remoção de crioprotetores (grupo 3) ou envasados e mergulhados obliquamente no nitrogênio líquido (grupo 4). A remoção dos crioprotetores foi realizada mediante imersão dos CCOs em uma solução de 0,3 M de sacarose em meio de manipulação com $20 \%$ de SEE, por cinco minutos, seguida da passagem em uma solução de $0,16 \mathrm{M}$ de sacarose em meio de manipulação com $20 \%$ de SEE, por cinco minutos.

Após a realização do tratamento específico, os CCOs imaturos dos grupos 2 a 4 foram transferidos para o meio de maturação (Meio TCM199 com sais de Earle, adicionado de 5,96mg/ml de Hepes; 2,2mg/ml de $\mathrm{NaHCO}_{3} ; 2,2 \mu \mathrm{g} / \mathrm{ml}$ de piruvato de sódio;

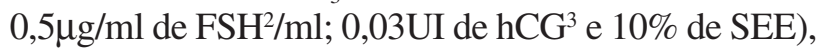
para incubação a $39^{\circ} \mathrm{C}$ em estufa com atmosfera de $5 \%$ de $\mathrm{CO}_{2}$ e máxima umidade relativa, onde permaneceram por 22 a 24 horas.

\section{Produção in vitro de embriões}

Os embriões foram produzidos in vitro em 10 repetições, utilizando os procedimentos experimentais descritos anteriormente por Vieira et al. [44], com pequenas modificações. Para a fecundação in vitro (FIV) foram selecionados espermatozóides pela técnica de "swim-up" a partir de sêmen congelado, proveniente de um touro com reconhecida eficiência na produção in vitro de embriões. A inseminação (dia zero=D0) foi obtida mediante a deposição de $20 \mathrm{ml}$ de meio com uma concentração final de $1 \times 10^{6}$ espermatozóides/ml as gotas de maturação contendo os CCOs e incubação por 18-22 horas, nas mesmas condições de cultivo descritas para a maturação.

Após a FIV, os prováveis zigotos foram desnudados das células do cumulus oophorus, mediante agitação mecânica em agitador de tubos (1800 rpm por 60 segundos), recuperados e lavados em meio de manipulação e transferidos para as respectivas placa de cultivo in vitro (CIV), contendo $400 \mathrm{ml}$ de meio SOFaaci [9], sob óleo mineral (M 8410) ${ }^{1}$. A incubação foi realizada a $39^{\circ} \mathrm{C}$ em estufa de cultivo com atmosfera de $5 \% \mathrm{CO}_{2}$ até a avaliação da taxa de clivagem 48 horas após a inseminação (dia 2=D2), quando foram removidas as estruturas não clivadas. Após isso, a placa de cultivo foi acondicionada em uma bolsa de plástico não permeável a gases [39] para incubação com atmosfera constante de $5 \%$ de $\mathrm{CO}_{2}, 5 \%$ de $\mathrm{O}_{2}, 90 \%$ de $\mathrm{N}_{2}$, máxima umidade relativa e temperatura de $39^{\circ} \mathrm{C}$ durante o restante do cultivo. A taxa de desenvolvimento embrionário até o estádio de blastocisto foi avaliada nos dia 7 e 8 (D7 e D8) do CIV.

\section{Análise da expressão gênica por RT-PCR semi-quanti- tativo}

A extração do RNA das amostras contendo as células do cumulus oophorus dos 5 CCOs em cada amostra foi realizada utilizando o reagente TRIzol ${ }^{4}$, de acordo com as instruções do fabricante. Para a captação específica do RNA mensageiro (mRNA) foi utilizado o produto comercial Dynabeads ${ }^{\circledR}$ mRNA $^{\mathrm{TM}}$ DIRECT Micro Kit ${ }^{5}$, conforme descrito anteriormente [24]. Antes da captação do mRNA, 0,1 pg de mRNA de alfa-hemoglobina (HBA) de coelho ${ }^{6}$ foi adicionado a cada amostra como um controle interno para ser analisado simultaneamente.

Os mRNAs isolados individualmente de células do cumulus oophorus de 5 CCOs em cada amostra foram transcritos reversamente em cDNA em uma solução contendo $4 \mu \mathrm{l}$ de tampão $5 \mathrm{X}$ First Strand Buffer (250 mM Tris-HCl pH 8,3; $375 \mathrm{mM} \mathrm{KCl} ; 15$ $\mathrm{mM} \mathrm{MgCl})^{4} ; 2 \mu \mathrm{lde}$ DTT $(50 \mathrm{mM})^{4} ; 1 \mu$ Oligo(dT) ${ }_{12-18}$ primer $(0,5 \mu \mathrm{g} / \mathrm{ml})^{4} ; 2 \mu \mathrm{l}$ de solução com $2,5 \mathrm{mM}$ de cada dNTP $^{4} ; 2 \mu 1$ de RNaseOUT ${ }^{\mathrm{TM}}$ Recombinant Ribonuclease Inhibitor (10 U/ $\mu \mathrm{l})^{4}$; e $100 \mathrm{U}$ de enzima M-MLV Reverse Transcriptase $(200 \mathrm{U} / \mu \mathrm{l})^{4} \mathrm{em}$ um volume final de $20 \mu \mathrm{l}$, em tubos cônicos de polipropileno de $0,5 \mathrm{ml}$. A reação de $\mathrm{RT}$ realizada a $37^{\circ} \mathrm{C}$ por 60 minutos seguida de aquecimento a $95^{\circ} \mathrm{C}$ por 10 minutos. Ao final da reação de transcrição reversa, as amostras de cDNA das células do cumulus foram diluídas para um volume final de $50 \mu$ l, com água livre de RNase, de maneira que cada amostra apresentasse o correspondente a $0,1 \mathrm{CCO}$ em cada $1 \mu \mathrm{l}$ do cDNA (equivalente CCO). Amostras com mRNA de HBA de coelho adicionadas às amostras de células do cumulus (globina + amostra) e amostras apenas com mRNA de HBA (globina pura) foram submetidas a RT-PCR.

A PCR foi realizada em tubos de $0,5 \mathrm{ml}$ contendo: $2 \mu \mathrm{l}$ de tampão 10X PCR Buffer (200 mM 
Tris- $\mathrm{HCl} \mathrm{pH} 8,4 ; 500 \mathrm{mM} \mathrm{KCl})^{4} ; 0,6 \mu \mathrm{lde} \mathrm{MgCl}_{2}$ $(50 \mathrm{mM})^{4} ; 1 \mu \mathrm{l}$ da solução de $10 \mathrm{mM}$ de $\mathrm{dNTP}^{4} ; 0,2 \mu \mathrm{l}$ de enzima Platinum ${ }^{\circledR}$ Taq DNA Polymerase $(5 \mathrm{U} / \mathrm{ml})^{4}$; $1 \mu \mathrm{l}(10$ ou $20 \mathrm{pmoles} / \mu \mathrm{l})$ de cada oligonucleotídeo ${ }^{4}$ (Tabela 1); 0,1 a 1,2 equivalente CCO $(1 \mu \mathrm{l}$ a $12 \mu \mathrm{l})$ de cDNA das amostras de células do cumulus, de acordo com o gene pesquisado, ou $1 \mathrm{pg}(1 \mathrm{pg} / \mu \mathrm{l}) \mathrm{de}$ cDNA de HBA de coelho; e água ultra-pura livre de DNase em quantidade suficiente para completar um volume final de $20 \mu \mathrm{l}$. A mistura foi coberta com óleo mineral (M-5904) ${ }^{1}$ e os tubos submetidos a PCR com desnaturação inicial de $94^{\circ} \mathrm{C}$ por 2 minutos, seguida de 33 ou 38 ciclos de amplificação de $94^{\circ} \mathrm{C}$ por 1 minuto, $56^{\circ} \mathrm{C}$ por 1 minuto e $72^{\circ} \mathrm{C}$ por 90 segundos, e um ciclo de extensão final de $72^{\circ} \mathrm{C}$ por 3 minutos. Foram utilizados 20 pmoles de oligonucleotídeos e 38 ciclos de amplificação para a link protein 1 e 10 pmoles de oligonucleotídeos e 33 ciclos para os demais fragmentos. Foi utilizado 1,2 equivalente $\mathrm{CCO}$ para link protein 1; 0,2 equivalente CCO para HAS2; 0,1 equivalente CCO para conexina 43; 0,3 equivalente CCO para HSP70-1; e 0,25 equivalente CCO para $H B A$ de coelho.

Os produtos da amplificado por PCR foram submetidos à eletroforese em gel de agarose (15510$019)^{7}$ a $2 \%$ em tampão TBE $0,5 X$ (45 mM Trisborato $\left.^{7} ; 1 \mathrm{mM} \mathrm{EDTA}{ }^{8}, \mathrm{pH} 8,0\right)$ contendo $0,5 \mu \mathrm{g} / \mathrm{ml}$ de brometo de etídio (E-8751) ${ }^{1}$. Cada gel foi fotografado com câmera digital (DC40 camera) ${ }^{9} \mathrm{e}$ a intensidade de cada banda obtida foi medida e a densidade óptica foi analisada utilizando o programa Scion Image $^{10}$. A quantidade relativa de mRNA de interesse foi calculada através da divisão da intensidade da banda de cada amostra de células do cumulus em cada grupo testado pela intensidade da banda de HBA de coelho da amostra correspondente. Para cada mRNA, foram realizadas 3 repetições experimentais com CCOs produzidos em diferentes rotinas de MIV.

\section{Análise estatística}

Os resultados de clivagem e de desenvolvimento embrionário até o estádio de blastocisto foram analisados utilizando o teste do Chi quadrado, complementado pela análise dos resíduos. A abundância relativa dos transcritos de interesse foi analisada pela ANOVA usando o pacote de programa SPSS $^{11}$.

\section{RESULTADOS}

Os dados de viabilidade embrionária obtidos no experimento de exposição dos CCOs à solução de vitrificação (SV) estão agrupados na Tabela 2. O grupo exposto à SV (ESV) e o grupo vitrificado (VSV) apresentaram resultados significativamente inferio-

Tabela 1. Sequência de bases dos oligonucleotídeos utilizados na técnica de RT-PCR para a amplificação de cDNA e número de pares de base $(\mathrm{pb})$ do fragmento amplificado.

\begin{tabular}{cccc}
\hline Genes & $\begin{array}{c}\text { Acesso no } \\
\text { GenBank }\end{array}$ & Sequência dos oligonucleotídeos & $\begin{array}{c}\text { Produto } \\
\text { amplificado }\end{array}$ \\
\hline GJA1 & NM_174068 & 5' GGGAAAGAGCGATCCTTACCACACTACCAC & 516pb \\
& 3' CCACCTCCAATGAAACAAAATGAACACCTA & \\
HAS2 & NM_174079 & 5' GCTTGACCCAGCATCATCTGTGG & 403pb \\
& & 3' CTGGTTAACCATCTGAGATATT & \\
HAPLN1 & NM_174288 & 5' GGTCTGTGCAATATCCCATC & 232pb \\
HSP70-1 & NM_174550 & 5' AAGGTGCTGGACAAGTGCCAGGAGGTGATT & 488pb \\
& & 3' ACTTGGAAGTAAACAGAAACGGGTGAAAAA & \\
HBA & NM_001082389 & 5' GCAGCCACGGTGGCGAGTAT & 257pb \\
& & 3' GTGGGACAGGAGCTTGAAAT & \\
\hline
\end{tabular}

GJA1 (gap junction protein, alpha 1,43kDa): conexina 43; HAPLN1 (hyaluronan and proteoglycan link protein 1): link protein; HAS2 (hyaluronan synthase): ácido hialurônico sintase 2; HBA (alpha-hemoglobin): alfa-hemoglobina; HSP70 1 (heat shock $70 \mathrm{kD}$ protein 1): proteína de choque térmico $70-1$. 
res ao grupo controle para a taxa de clivagem $(\mathrm{p}=$ $0,0001)$ e desenvolvimento embrionário até blastocisto D7 $(\mathrm{p}=0,0001)$ e blastocisto $\mathrm{D} 7+\mathrm{D} 8(\mathrm{p}=$ 0,0001).

A análise das fotografias realizadas dos géis após a eletroforese, através da medição da densidade óptica de cada banda dos fragmentos de cDNA, permitiu estabelecer um valor de abundância relativa para cada amostra, relacionada com a expressão dos transcritos. A média e o desvio padrão dos valores de abundância relativa dos transcritos obtidos a partir das células do cumulus oophorus de 5 CCOs bovinos em cada um dos quatro grupos experimentais, após três repetições, são apresentados na Figura 1. Entre os diferentes grupos de CCOs testados não foi observada diferença significativa na abundância relativa dos transcritos de link protein $(\mathrm{p}=0,486), H A S 2$ $(\mathrm{p}=0,394)$, conexina $43(\mathrm{p}=0,116)$ e HSP70-1 $(\mathrm{p}=0,248)$.

Tabela 2. Taxa de clivagem e de desenvolvimento até o estádio de blastocisto de oócitos bovinos imaturos expostos à solução de vitrificação (ESV) ou vitrificados (VSV).

\begin{tabular}{ccccc}
\hline Grupos & $\begin{array}{c}\text { Número } \\
\text { de oócitos }\end{array}$ & Clivagem & \multicolumn{2}{c}{ Blastocistos } \\
& & $\mathrm{N}(\%)$ & $\mathrm{N}(\%)$ & $\mathrm{D} 7+\mathrm{D} 8$ \\
\hline Controle & 359 & $287^{\mathrm{a}}(79,9)$ & $131^{\mathrm{a}}(36,5)$ & $\mathrm{N}(\%)$ \\
ESV & 118 & $71^{\mathrm{b}}(60,1)$ & $20^{\mathrm{b}}(16,9)$ & $25^{\mathrm{a}}(40,4)$ \\
VSV & 217 & $94^{\mathrm{c}}(43,3)$ & $9^{\mathrm{c}}(4,1)$ & $10^{\mathrm{c}}(4,6)$ \\
\hline
\end{tabular}

a, b, c: números seguidos de letras desiguais na coluna diferem estatisticamente pelo teste do Qui-quadrado $(\mathrm{p}=0,0001)$.

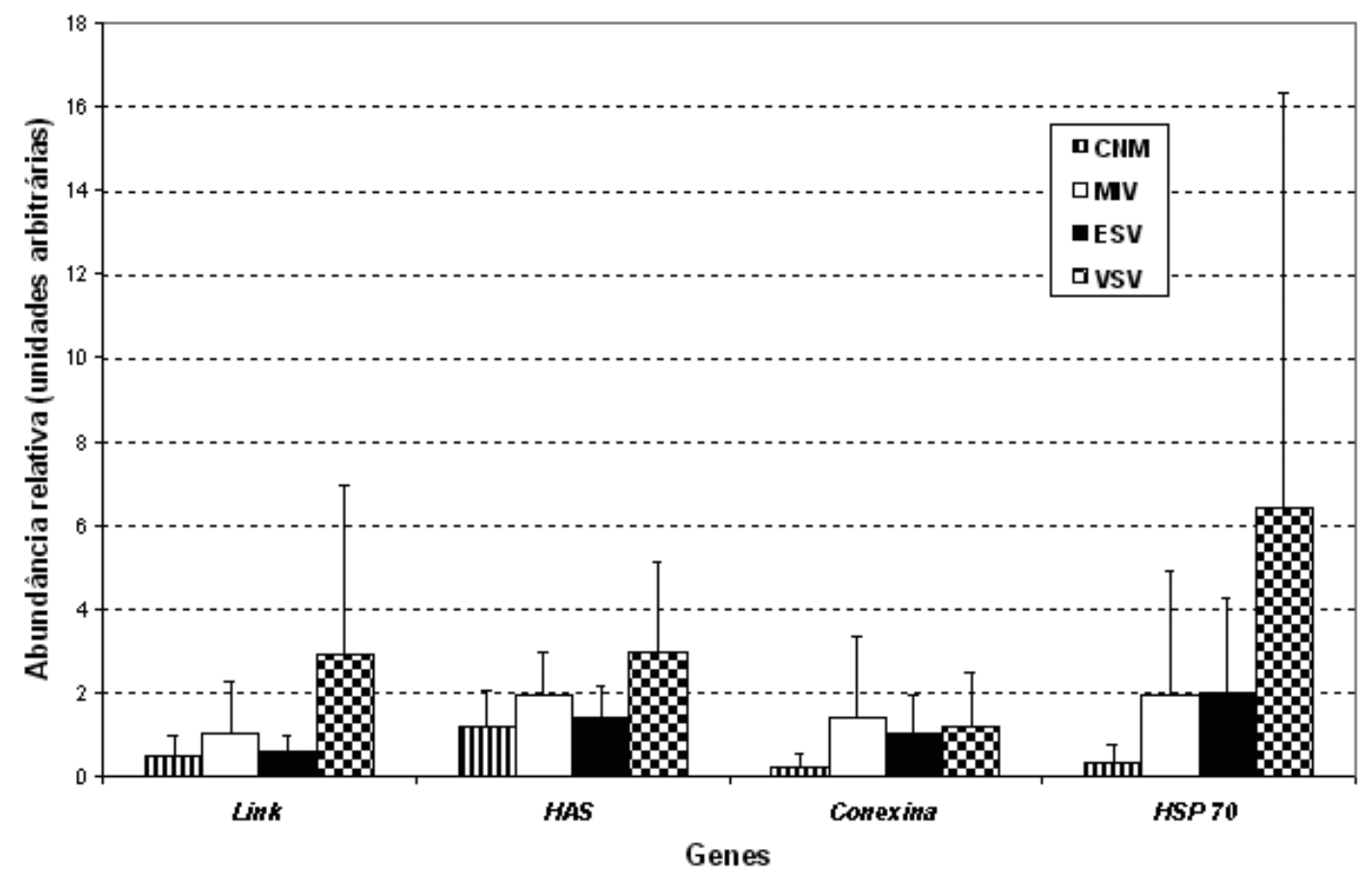

Figura 1. Abundância relativa do mRNA (média \pm desvio padrão) de link protein, HAS2, conexina 43 e HSP70-1 nos diferentes grupos de células do cumulus bovinas. Grupo 1 (CNM - CCOs não submetidos à maturação in vitro; Grupo 2 (MIV - CCOs submetidos à maturação in vitro); Grupo 3 (ESV - CCOs maturados após exposição à solução de vitrificação); Grupo 4 (VSV - CCOs maturados após a vitrificação). 


\section{DISCUSSÃO}

Apesar dos avanços e da importância da criopreservação de ovários e oócitos, um dos mais difíceis tipos celulares de serem criopreservados ainda é o oócito [6]. Após a criopreservação, na qual a vitrificação aparece como o método com melhores resultados, o oócito apresenta comprometimento da sua capacidade de desenvolvimento. A vitrificação procura evitar a formação de cristais de gelo dentro da célula através do grande aumento da viscosidade da solução utilizada. Porém, tanto a alta concentração dos crioprotetores, que pode tornar-se tóxica para as células quando utilizadas em temperatura inadequada, como o resfriamento, provocam danos celulares $[4,40]$.

No presente trabalho, a solução de EG, combinado ao DMSO e sacarose, mostrou resultados de clivagem e desenvolvimento embrionário até o estádio de blastocisto inferiores ao grupo controle, como já foi observado anteriormente por outros autores $[1,11,43,45]$. Oócitos e embriões sofrem consideráveis danos na sua estrutura e funções durante a criopreservação e provavelmente as células da granulosa também sofram algum tipo de dano. Entretanto, de alguma forma, parte destas células possui a capacidade de reparar parcial ou completamente os danos, prosseguindo seu desenvolvimento normal [40].

O EG é bastante utilizado para vitrificação de oócitos imaturos bovinos por possuir alta permeabilidade e baixa toxicidade; já o DMSO tem uma ação tóxica que provoca desarranjo dos microtúbulos no oócito [4]. Alguns dos oócitos vitrificados não realizam a extrusão normal do corpúsculo polar mesmo após a separação dos cromossomos, o que indica capacidade de maturar normalmente atingindo o estágio de telófase I [4]. Entretanto, danos em algum fator regulador chave envolvido na extrusão, observados pelas diferenças na atividade metabólica das mitocôndrias dos oócitos vitrificados em relação aos do grupo controle [1] e alterações no conteúdo de fosfolipídios e composição de ácidos graxos [12], podem explicar a baixa sobrevivência oocitária após a vitrificação. Alterações nas mitocôndrias e lipídios após a criopreservação poderiam afetar a fecundação e o processo de desenvolvimento posterior. Por outro lado, o dano causado pela criopreservação poderia levar a destruição do contato intercelular entre as células do cumulus e o oócito, principalmente através das junções comunicantes [11].

Experimentos que avaliam a estrutura dos CCOs criopreservados submetidos a maturação in vitro não examinam a influência da vitrificação sobre as células da granulosa [4,21]. No que se refere à análise da expressão de genes relacionados ao processo de maturação in vitro, a literatura dá maior ênfase à expressão de transcritos do oócito, não avaliando, geralmente, a expressão em células da granulosa. Este é o primeiro trabalho que avalia a expressão gênica em células do cumulus oophorus de CCOs imaturos vitrificados na espécie bovina. A avaliação da qualidade dos CCOs, baseada na análise da expressão de genes relacionados ao processo de maturação in vitro, pode ajudar a compreender melhor o que acontece durante a produção in vitro, especialmente nesta fase inicial [28]. As informações sobre expressão gênica das células da granulosa após a vitrificação são escassas na literatura consultada. Não há ainda uma padronização do processo de RT-PCR para avaliação da abundância de mRNA em diferentes amostras de oócitos e células da granulosa [23,48]. Os trabalhos basicamente discutem a participação das células da granulosa no desenvolvimento do oócito e os processos envolvidos na interação entre as duas estruturas [10,28,36,46,49].

Durante a maturação, ocorre secreção de grandes quantidades de ácido hialurônico (HA) e outras proteínas que originam uma matriz extracelular gelatinosa envolvida na expansão do complexo cumulus oophorus-oócito [13,29]. Quando o HA é adicionado ao meio de maturação e cultivo há um aumento do potencial de desenvolvimento de oócitos [19] e embriões [8,32] bovinos. A expressão da proteína ácido hialurônico sintase 2 (HAS2), envolvida com a síntese de HA pelas células do cumulus, tem sido relacionada ao desenvolvimento da competência do oócito [7]. A importância da HAS está relacionada com o processo de expansão da matriz [10]. O agregado protéico formado entre o HA e as proteoglicanas, responsável por manter a integridade e dar suporte às funções da matriz extracelular, é dependente da link protein (HAPLN1), proteína produzida pelas células do cumulus $[15,34]$ e envolvida também na expansão do CCO [31,48].

A importância dos genes HAS2 e link protein durante a maturação sugere uma possível diferença 
na abundância relativa do mRNA de ambos quando comparados CCOs antes e após a maturação. Entretanto, no presente trabalho, esta diferença não foi demonstrada, apesar das médias de abundância relativa após a maturação serem mais altas. Da mesma forma, a expectativa de que a exposição ao crioprotetor e a vitrificação levassem à alteração no perfil de expressão destes genes por interferir na viabilidade de síntese das células do cumulus, não pôde ser observada, pois houve uma variabilidade muito grande no perfil de abundância de mRNA entre as diferentes repetições para os grupos de CCOs.

A família de genes conexina expressa proteínas que formam junções comunicantes importantes para comunicação célula-célula e resposta coordenada. O mRNA e a proteína do gene conexina 43 está presente nos CCOs bovinos durante a maturação in vitro $[3,47]$. As junções comunicantes têm uma função importante durante a maturação in vitro do oócito bovino, uma vez que o bloqueio da sinalização através das junções comunicantes ou a redução da proteína conexina 43 resulta em diminuição das taxas de maturação [47]. Além disso, a expansão das células do cumulus, evento importante relacionado com a maturação, é acompanhada de modificações nos canais transmembrana formados pela conexina 43 [5]. No presente trabalho não se observou diferença estatística na abundância relativa do mRNA de conexina 43 entre os grupos de CCOs imaturos e após a maturação in vitro, apesar das médias de abundância relativa de todos os grupos de CCOs pósmaturação serem mais altas, principalmente no grupo de CCOs maturados sem tratamento com crioprotetor. O processo de vitrificação expõe as células a substâncias que apresentam algum grau de toxicidade e que, por sua vez, causam certo tipo de lesão ou morte celular. Seria esperado que a exposição dos CCOs aos crioprotetores ou à vitrificação causassem alguma interferência na viabilidade das células do cumulus e no arranjo protéico intercelular, afetando a expressão da conexina 43. Este efeito não foi observado quando comparada a abundância de mRNA de conexina 43 entre os grupos de CCOs maturados. Provavelmente, exista uma grande variação entre os CCOs selecionados para os experimentos e na resposta destes aos diferentes tratamentos, pois os resultados mostram uma variabilidade muito grande no perfil de abundância de mRNA entre as diferentes repetições para os grupos de CCOs. Já foi relatada [37] grande variação nos níveis de mRNA de conexina 43 nas células da granulosa de folículos humanos e, provavelmente, esta resposta variável ocorre em função da grande quantidade de células da granulosa presentes no CCO.

As HSPs estão envolvidas na regulação da apoptose celular e a HSP70 previne tanto a morte celular dependente como a independente de caspase [27]. O aumento da abundância dos transcritos de HSP70 em embriões bovinos vitrificados, comparados com embriões não criopreservados é indicativo de uma resposta ao estresse e da diminuição da qualidade dos embriões, em função dos danos causados pela vitrificação [26]. O acúmulo de transcritos durante o período de crescimento do oócito é fundamental para o desenvolvimento inicial até a ativação do genoma embrionário. Entretanto, durante a MIV, os oócitos e as células da granulosa são expostos a uma série de suplementos, como soro ou BSA, que podem afetar a transcrição dos genes. Em blastocistos bovinos produzidos in vitro, alguns autores consideram que o aumento da abundância relativa de HSP70 está relacionada com a suplementação do meio com BSA ou soro durante a maturação dos oócitos $[28,46]$, enquanto outros mostram que a suplementação protéica com BSA ou soro no meio de maturação ou cultivo não alteram o perfil de abundância do mRNA de HSP70 dos embriões [16,24]. No presente trabalho, a resposta ao estresse da exposição dos CCOs imaturos aos crioprotetores e ao processo de vitrificação não causou diferença significativa na abundância relativa dos transcritos de $H S P 70$.

Diferentes genes expostos às mesmas condições experimentais podem ser induzidos diferencialmente dependendo de qual processo físico é afetado. Neste trabalho, apesar da queda da viabilidade dos oócitos após a exposição à SV ou vitrificação, não foi observada diferença na expressão dos genes entre CCOs imaturos e após a MIV, ou entre CCOs maturados após a exposição ou vitrificação. Entretanto, foram observadas grandes variações no perfil de abundância de mRNA entre as diferentes repetições para os grupos de CCOs expostos ao mesmo tratamento. Isto sugere que a falta de significância estatística para a abundância relativa de mRNA entre os tratamentos pode ser devida a grande variação entre as amostras de CCOs, como é relatado em traba- 
lhos com embriões bovinos [2,24]. Outra possibilidade para esta variação no perfil de abundância relativa entre os grupos pode estar relacionada como sistema de MIV utilizado para os experimentos; a suplementação do meio com soro tem sido relacionada à variabilidade de resposta de embriões [14] e de CCOs bovinos in vitro [3].

\section{CONCLUSÕES}

A exposição dos complexos cumulus oophorus-oócito (CCOs) bovinos às soluções crioprotetoras e à vitrificação diminuiram a viabilidade dos oócitos e sua posterior capacidade de desenvolvimento embrionário in vitro. As condições de maturação in vitro, a exposição às soluções crioprotetoras e a vitrificação não afetaram a expressão dos transcritos nas células do cumulus oophorus bovinos. Os genes utilizados não se mostraram bons marcadores para a avaliação do processo maturação e vitrificação de CCOs no que se refere ao comportamento das células do $\mathrm{cu}$ mulus oophorus bovinos.

\section{NOTAS INFORMATIVAS}

${ }^{1}$ Sigma Chemical Co., St. Louis, MO, EUA.

${ }^{2}$ Folltropin ${ }^{\circledR}$, Vetrepharm, Ontário, Canadá.

${ }^{3}$ Profasi ${ }^{\circledR}$, Serono, São Paulo, Brasil.

${ }^{4}$ Invitrogen ${ }^{\mathrm{TM}}$, São Paulo, Brasil.

${ }^{5}$ DYNAL, Oslo, Noruega.

${ }^{6} \mathrm{BRL}$, Gaithersburg, MD, EUA.

${ }^{7}$ GIBCO BRL, Grand Island, NY, EUA.

${ }^{8}$ MERK, Darmstadt, Alemanha.

${ }^{9}$ Eastman Kodak Company, Rochester, NY, EUA.

${ }^{10}$ Scion Corporation, Frederick, MD, EUA.

${ }^{11}$ SPSS Inc., Chicago, IL., EUA

\section{REFERÊNCIAS}

1 Abe Y., Hara K., Matsumoto H., Kobayashi J., Sasada H., Ekwall H., Rodriguez-Martinez H. \& Sato E. 2005. Feasibility of a nylon-mesh holder for vitrification of bovine germinal vesicle oocytes in subsequent production of viable blastocysts. Biology of Reproduction. 72(6): 1416-1420.

2 Bilodeau-Goeseels S. \& Panich P. 2002. Effects of oocyte quality on development and transcriptional activity in early embryos. Animal Reproduction Science. 71(3-4): 143-155.

3 Calder M.D., Caveney A.N., Smith L.C. \& Watson A.J. 2003. Responsiveness of bovine cumulus-oocyte-complexes (COC) to porcine and recombinant human FSH, and the effect of COC quality on gonadotropin receptor and $\mathrm{Cx} 43$ marker gene mRNAs during maturation in vitro. Reproductive Biology and Endocrinology. 1: 14. [Fonte: <http:// www.ncbi.nlm.nih.gov/ pmc/articles/PMC151788/pdf/1477-7827-1-14.pdf>].

4 Cetin Y. \& Bastan A. 2006. Cryopreservation of immature bovine oocytes by vitrication in straws. Animal Reproduction Science. 92(1-2): 29-36.

5 Dell'Aquila M.E., Caillaud M., Maritati F., Martoriati A., Gerard N., Aiudi G., Minoia P. \& Goudet G. 2004. Cumulus expansion, nuclear maturation and connexin 43 , cyclooxygenase-2 and FSH receptor mRNA expression in equine cumulusoocyte complexes cultured in vitro in the presence of FSH and precursors for hyaluronic acid synthesis. Reproductive Biology and Endocrinology. 2: 44. [Fonte: <http://www.ncbi.nlm.nih.gov/pmc/articles/PMC446214/pdf/1477-7827-244.pdf>].

6 Diez C., Duque P., Gómez E., Hidalgo C.O., Tamargo C., RodriguezA., Fernández, L., de la Varga S., FernándezA., Facal N. \& Carbajo M. 2005. Bovine oocyte vitrication before or after meiotic arrest: effects on ultrastructure and developmental ability. Theriogenology. 64(2): 317-333.

7 Dunning K.R., Lane M., Brown H.M., Yeo C., Robker R.L. \& Russel D.L. 2007. Altered composition of the cumulus-oocyte complex matrix during in vitro maturation of oocytes. Human Reproduction. 22(11): 2842-2850.

8 Furnus C.C., De Matos D.G. \& Martinez A.G. 1998. Effect of hyaluronic acid on development of in vitro produced bovine embryos. Theriogenology. 49(8): 1489-1499.

9 Holm P., Booth P.J., Schmidt M.H., Greve T. \& Callesen H. 1999. High bovine blastocyst development in a static in vitro production system using SOFaa medium supplemented with sodium citrate and myo-inositol with or without serum proteins. Theriogenology. 52(4): 683-700.

10 Irving-Rodgers H.F. \& Rodgers R.J. 2005. Extracellular matrix in ovarian follicular development and disease. Cell and Tissue Research. 322(1): 89-98.

11 Kim D.H., Park H.S., Kim S.W., Hwang I.S., Yang B.C., Im G.S., Chung H.J., Seong H.W., Moon S.J. \& Yang B.S. 2007. Vitrification of immature bovine oocytes by the microdrop method. Journal of Reproduction and Development. 53(4): 843-851. 
12 Kim J.Y., Kinoshita M., Ohnishi M. \& Fukui Y. 2001. Lipid and fatty acid analysis of fresh and frozen-thawed immature and in vitro matured bovine oocytes. Reproduction. 122(1): 131-138.

13 Kimura N., Konno Y., Miyoshi K., Matsumoto H. \& Sato E. 2002. Expression of hyaluronan synthases and CD44 messenger RNAs in porcine cumulus-oocyte complexes during in vitro maturation. Biology of Reproduction. 66(3): 707-717.

14 Knijn H.M., Wrenzycki C., Hendriksen P.J., Vos P.L., Herrmann D., Van Der Weijden C.G., Niemann H. \& Dieleman S.J. 2002. Effects of oocyte maturation regimen on the relative abundance of gene transcripts in bovine blastocysts derived in vitro or in vivo. Reproduction. 124(3): 365-375.

15 Kobayashi H., Sun G.W., Hirashima Y. \& Terao T. 1999. Identification of link protein during follicle development and cumulus cells cultures in rats. Endocrinology. 140(8): 3835-3842.

16 Lazzari G., Wrenzycky C., Herrmann D., Duchi R., Kruip T., Niemann H. \& Galli C. 2002. Cellular and molecular deviations in bovine in vitro-produced embryos are related to the large offspring syndrome. Biology of Reproduction. 67(3): 767-775.

17 Lehmkuhl R.C., Mezzalira A., Vieira A.D., Barbieri D.P., Machado M.F., Rubin M.I.B. \& Silva C.A.M. 2002. Viabilidade de oócitos bovinos mantidos em líquido folicular. Ars Veterinaria. 18(3): 273-279.

18 Loos F., Van Vliet C., Van Maurik P. \& Kruip T. A. 1989. Morphology of immature bovine oocytes. Gamete Research. 24(2): 197-204.

19 Marquant-le Guiene B., Guyader-Joly C., Ponchon S., Delalleau N. \& Humblot P. 2002. Effect of hyaluronic acid in a serum free maturation medium on bovine embryo development. Theriogenology. 51(1): 386.

20 Martino A., Songsasen N. \& Leibo S.P. 1996. Development into blastocysts of bovine oocytes cryopreserved by ultrarapid cooling. Biology of Reproduction. 54(5): 1059-1069.

21 Martins R.D., Costa E.P., Chagas J.S.C., Ignacio F.S., Torrres C.A.A. \& McManus C. 2005. Effects of vitrification of immature bovine oocytes on in vitro maturation. Animal Reproduction. 2(2): 128-134.

22 Massip A. 2003. Cryopreservation of bovine oocytes: Current status and recent developments. Reproduction Nutrition and Development. 43(4): 325-330.

23 Nemcova L., Machtkova M., Hanzalova K., Horakova J. \& Kanka J. 2006. Gene expression in bovine embryos derived from oocytes with different developmental competence collected at the dened follicular developmental stage. Theriogenology. 65(7): 1254-1264.

24 Oliveira A.T.D., Lopes R.F.F. \& Rodrigues J.L. 2006. Gene expression and developmental competence of bovine embryos produced in vitro with different serum concentrations. Reproduction in Domestic Animals. 41(2): 129-136.

25 Papis K., Shimizu M. \& Izaike Y. 1999. The effect of gentle pre-equilibration on survival and development rates of bovine in vitro matured oocytes vitrified in droplets. Theriogenology. 51(1): 173.

26 Park S.Y., Kim E.Y., Cui X.S., Tae J.C., Lee W.D., Kim N.H., Park S.P. \& Lim J.H. 2006. Increase in DNA fragmentation and apoptosis-related gene expression in frozen-thawed bovine blastocysts. Zygote. 14(2): 125-131.

27 Ravagnan L., Gurbuxani S., Susin S.A., Maisse C., Daugas E., Zamzami N., Mak T., Jaattela M., Penninger J.M., Garrido C. \& Kroemer G. 2001. Heat-shock protein 70 antagonizes of apoptosis-inducing factor. Nature Cell Biology. 3(9): 839843.

28 Sagirkaya H., Misirlioglu M., Kaya A., First N.L., Parrish J.J. \& Memili E. 2007. Developmental potential of bovine oocytes cultured in different maturation and culture conditions. Animal Reproduction Science. 101(3-4): 225-240.

29 Salustri A., Camaioni A., Di Giacomo M., Fulop C. \& Hascall V.C. 1999. Hyaluronan and proteoglycan in ovarian follicles. Human Reproduction Update. 5(4): 293-301.

30 Santos R.M., Barreta M.H., Frajblat M., Cucco D.C., Mezzalira J.C., Bunn S., Cruz F.B., VieiraA.D. \& MezzaliraA. 2006. Vacuum-cooled liquid nitrogen increases the developmental ability of vitrified-warmed bovine oocytes. Ciência Rural. 36(5): 1501-1506.

31 Spicer A.P., Joo A. \& Bowling Jr. R.A. 2003. A hyaluronan binding link protein gene family whose members are physically linked adjacent to chrondroitin sulfate proteoglycan core protein genes. The Journal of Biological Chemistry. 278(23): 21083-21091.

32 Stojkovic M., Thompson J.G. \& Tervit H.R. 1999. Effects of hyaluronic acid supplementation on in vitro development of bovine embryos in a two-step culture system. Theriogenology. 51(1): 254.

33 Suo L., Zhou G.B., Meng Q.G., Yan C.L., Fan Z.Q., Zhao X.M., Fu X.W., Wang Y.P., Zhang Q.J. \& Zhu S.E. 2008. OPS vitrification of mouse immature oocytes before or after meiosis: the effect on cumulus cells maintenance and subsequent development. Zygote. 17(1): 71-77. 
34 Sun G.W., Kobayashi H. \& Terao T. 1999. Expression of link protein during mouse folicular development. Journal of Histochemistry and Cytochemistry. 47(11): 1433-1442.

35 Tangue S., Van Soom A., Nauwynck H., Coryn M. \& De Kruif A. 2002. Minireview: functions of the cumulus oophorus during oocyte maturation, ovulation, and fertilization. Molecular Reproduction and Development. 61(3): 414-424.

36 Tirelli M., Basini G., Grasselli F., Bianco F. \& Tamanini, F. 2005. Cryopreservation of pig granulosa cells: effect of FSH addition to freezing medium. Domestic Animal Endocrinology. 28(1): 17-33.

37 Tsai M.Y., Lan K.C., Huang K.E., Huang F.J., Kung F.T. \& Chang S.Y. 2003. Signicance of mRNA levels of connexin37, connexin43, and connexin45 in luteinized granulosa cells of controlled hyperstimulated follicles. Fertility and Sterility. 80(6): $1437-1443$.

38 Vajta G. 2000. Vitrification of the oocytes and embryos of domestic animals. Animal Reproduction Science. 60-61: 357364.

39 Vajta G., Holm P., Greve T. \& Callesen H. 1997. The submarine incubation system, a new tool for in vitro embryo culture: a technique report. Theriogenology. 48(8): 1379-1385.

40 Vajta G. \& Kuwayama M. 2006. Improving cryopreservation systems. Theriogenology. 65(1): 236-244.

41 Vajta G., Kuwayama M., Holm P., Booth P.J., Jacobsen H., Greve T. \& Callesen H. 1998. A new way to avoid cryoinjuries of mammalian ova and embryos: the OPS vitrification. Molecular Reproduction and Development. 51(1): 53-58.

42 Van Soom A., Tanghe S., De Pauw I., Maes D. \& De Kruif A. 2002. Function of cumulus oophorus before and during mammalian fertilization. Reproduction in Domestic Animals. 37(3): 144-151.

43 Vieira A.D., Forell F., Feltrin C. \& Rodrigues J.L. 2008. Calves born after direct transfer of vitrified bovine in vitroproduced blastocysts derived from vitrified immature oocytes. Reproduction in Domestic Animals. 43(3): 314-318.

44 Vieira A.D., Forell F., Feltrin C., Santos L.C. \& Rodrigues J.L. 2006. Bovine in vitro production protocol: does it really influence embryo cryotolerance? Acta Scientiae Veterinariae. 34(1): 57-63.

45 Vieira A.D., Mezzalira A., Barbieri D.P., Lehmkuhl R.C., Rubin M.I.B. \& Vajta G. 2002. Calves born after open straw vitrification of immature bovine oocytes. Cryobiology. 45(1): 91-94.

46 VirequeA.A., Camargo L.S.A., Serapia R.V., Rosa e SilvaA.A.M, Watanabe Y.F., Ferreira E.M., Navarro P.A.A.S., Martins W.P. \& Ferriani R.A. 2009. Preimplantation development and expression of Hsp-70 and Bax genes in bovine blastocysts derived from oocytes matured in alpha-MEM supplemented with growth factors and synthetic macromolecules. Theriogenology. 71(4): 620-627.

47 Vozzi C., FormentonA., ChansonA., SennA., Sahli R., Shaw P., Nicod P., Germond M. \& Haefliger J.A. 2001. Involvement of connexin 43 in meiotic maturation of bovine oocytes. Reproduction. 122(4): 619-628.

48 Wrenzycki C., Herrmann D. \& Niemann H. 2007. Messenger RNA in oocytes and embryos in relation to embryo viability. Theriogenology. 68(Suppl. 1): S77-S83.

49 Yokoo M., Tientha P., Kimura N., Niwa K., Sato E. \& Rodrigues-Martinez H. 2002. Localization of the hyaluronan receptor CD44 in porcine cumulus cells during in vivo and in vitro maturation. Zygote. 10(4): 317-326. 